\title{
How to Carry Out Benign Social Construction and Management through Sociological Perspective
}

\author{
Yang Jing \\ Shaanxi Police College, Department of ideological and political education
}

\author{
Keywords: Sociology; Field of View; Benign; Social Construction; Management
}

\begin{abstract}
Sociology is a set of discipline system which is very helpful for social behavior and human group research. From the perspective of political science, social governance and management, sociology is a way to seek to the goal of improving social welfare by using scientific argumentation and empirical methods and combining with the basic structure and activity routines of human society. Social construction and management are broad and narrow in two different ways. Generally speaking, the core role of government organization, profit organization and social organization can be fully used through the cooperation of these three basic structural departments and combination with the theory and practice of social governance. Sociology is connected with philosophic concept and political concept. Therefore, in order to promote social harmony and progress and save social governance cost, the long-term mechanism of pluralistic coordinate social interests community would be the social management innovation which we want to specifically study in this paper.
\end{abstract}

\section{Introduction}

It relates to functional and structural aspects of social governance to carry out benign social construction and management on the perspective of sociology. In order to be able to alleviate the pressure of social management, developing social organizations to carry out social construction assistance and management is a right behavior. Establish long - term social interests coordinated development relation, vigorously promote the innovative reform on social construction and management are the extension of our party and government's political reform theory. At this stage, there is certainly still a lot of space for the growth of our country's exploration on socialist society construction. Therefore, updating the concept of social management and promoting the promotion role of sociology on social governance and management are good things for nation and people. It is a measure that in line with the aspirations of people and the fundamental interests of the state.

\section{The Development Background of Sociological Theory and Vision}

What is sociological vision? The so-called sociological vision is actually to combine itself with the relevant theory of sociology from the sociological point of view to understand the characteristics of each social management behavior and the purpose that this behavior should achieve. Under the coordination of reasonable behavior and restraint mechanisms, to analyze the relationship between unilateral acts of social individual or group acts. At the same time, to explain the different sociological development theory combining with the phenomenon and environment of social background. Therefore, from the sociological point of view, we must first explore the relationship between social behaviors and social events, analyze the formation and development of a social action and its evolution and ultimate impact. From a broad perspective, the sociological point of view is a relatively broad method to analyze problems. From the perspective of definition to do the basic preparation of social construction and management, then explore its current situation, characteristics and causes, understand the relevant issues and point out proposals and initiatives.

Why social management should be carried out from the perspective of sociology? The reason why we analyze sociology from the perspective of social management is that the social management can be divided into broad and narrow sense. The social construction and management in broad sense is basic concept of the whole social management and construction. It contains political subsystems, economic subsystems, ideology and culture subsystems and social life 
subsystems. For this huge social system construction and management work, we can see that social management need the whole society to work together according to political and economic development management scope. Of course, the core of social management and social construction lies in the constraints and management on each different subsystem. The management and promotion function of sociology for social and political life is extremely obvious. From the perspective of sociology to explore social construction and management work, we can see that benign social management and construction work is a worldwide trend. To better improve the social structure, lay a harmonious foundation for social construction, analyzing various things and phenomena from a sociological point of view is necessary. It is also important to understand the setting and operation of social organization and the evolution and historical develop process of social phenomena. At the same time, sociology can better promote the government management work. It is helpful for adjusting the center of government management work from the perspective of sociological theory. Sociology can also provide theoretical basis for the government stage work.

The development and application of sociological theory and practice in China. China's sociology has now entered a stage of vigorous development. For decades, the increasingly mature sociological theory has acquired fruitful research results. Research scholars who focus on China problems did researches in interdisciplinary fields about the major economic and social problems that took place in Chinese society and have established its own characteristic research system. Traditional studies tend to use sociological perspectives and do research from a practical point of view. Research areas are more inclined to urban-rural relations, urbanization issues, poverty, gap between the rich and poor and social environment. And now the sociology studies gradually tend to social development related issues. It provided a rich basis for social policy formulation, social construction and management. With the breakthrough which China's sociological theory has gained in reflection and reconstruction aspects, people realized the important role of sociological theory on solving social problems generated in the rapid changes and reorganization of all society sectors. And take use of its academic permeability to establish a set of highly disciplined disciplines. In recent years, the sociological theory and practice are more inclined to the improvement and use of social statistical analysis methods and to find out the description of data statistics and social changes from the theory. Researchers pay more attention to empirical research methods for theoretical deduction. Therefore, the sociological social statistical analysis method has accumulated rich data statistics and analysis experience through quantitative and qualitative analysis. It made the sociological theory reflect a certain scientific development trend in social construction and management process.

What's more, with the constantly strengthen of sociology's division of labor and specialization degree, the juncture of traditional research field and the emerging edge disciplines of sociology has become an interesting research direction of many scholars. Dividing subjects no longer simply take research object as a boundary, but to distribute sociology to all aspects of social management.

\section{The Development Connotation of Social Development and Management}

Generalized society construction and management. The academic purpose of sociology is to predict the development of society, to explore the development and operation of society and to coordinate various factors. Broad social construction often focuses on overall development and operation situation of the society. It coordinates benign and coordinated growth of society, researches social solidarity, social integration, social conflict and social development in the process of focusing on the interaction and relevance of each social subsystem and segment. From a broad social construction and management perspective, it promotes the sustainable development of society, seizes the essence of socialist sociology and guides the social atmosphere to a more equitable and stable direction.

Narrow social construction and management. The so-called narrow sense of social construction and management refers to the social construction process of self-development and improvement in social field. In other words, it focuses on social life and relations in population and education issues and solves people's employment and welfare issues. Especially in the modern, 
increasingly numerous social production products, the proportion of non-material products is becoming more and more lager. Therefore, the social development and systematic research on the future development of human beings and promoting their research theory more specific and targeted become the research direction of narrow social construction and management. Therefore, the study on social welfare, civil society, population theory, education theory and modern consumption theory has become the focus of research.

Benign society evaluation criteria for construction and management. First, operability principle

Modern sociological research needs to combine theory deeply with practice and actual operation. Therefore, the operationalization of social construction has become one of the evaluation criteria of benign social construction and management. In other words, we hope to find an evaluation channel of benign social construction and management through the analysis of sociological theory. Regardless of which specific governance model is used, as long as we can achieve the ultimate goal of social construction theory according to local condition, it is possible to study the welfare of people and a series of social problems on the basis of social construction practice and find reasonable and timely social management and governance methods.

Second, institutional principle

All social governance methods and theories should be well documented. In the process of social governance and management, we should not only meet the needs of development of sociological theory but also combine with the new features of social practice and development. In our country, in order to protect the interests of broad masses of the people, all the social construction and management methods can't be made simply by government or social organization. The relevant social management and construction system should be carried forward on the basis of public opinion. Some scholars think that society is a standardized system. For the governance of society, the premise is to use a set of standardized process and system to adapt to social adaptability, complexity and autonomy. To balance the gambling relations between various forces in society with institutionalized theoretical framework. Use the core concept of institutional economics to find a more clarity and applicable research framework to solve social problems.

\section{The Structural Analysis of Social Construction and Management}

The theoretical basis of sociological vision. Social organization system can be divided into three departments. In the modern society increasingly divided ownership classification, the three big departments are mutual restraint and mutual independence. The first sector is state and government organizations which are the public power field in China. The second sector is society which belongs to economic field. The third sector is social organization which is the public field. From the sociological point of view, the third sector can be divided into for-profit organizations and non-profit organizations. They can work together for social management and construction as three modern social entities. The structural premise of social construction and management is based on the social symbiosis between the three departments to build stable social sector structure in dynamic interaction process.

The relationships and dependencies between three big departments. The three departments of our society are interrelated and dependent. The distinctive substantive organizational structures they followed have penetrated into all socio-economic and political areas. But the three departments have their own duties in political rights and the process of social management. Their power scopes and enforcement degree are inalienable. The relationship and dependency between the three departments of society is manifested in their complementarity. National and economic fields can't be ignored and social organization probably can't get its due attention and respect. In China, many social organizations are nonprofit public welfare organizations, and the boundaries between their commonweal and profitability are relatively obscure. Therefore, the proportion and power size of the three fields have a certain degree of imbalance. This kind of dependency of the three big departments is both scientific but also helpless.

The coordination of the three major social construction function subjects. The three main 
social construction and management function subjects directly decide the effect of social construction and management. In the government's point of view, the main body supervision and management functions should be done well and onside and no dislocation. As social and economic fields, when introducing the research content of public power and public order, the social application function should be better exerted. The function of social organizations in the three main function subjects mainly lies into effectively making up for the situation of social market failure and government failure and reducing the cost of social management. Effectively harmonizing the cooperation and promotion relations between the three departments is the structural basis to build a harmonious society.

\section{Analysis of the Social Construction and Management Concept}

Social construction on the deep idea of people - oriented. Adhere to the core of people - oriented scientific development. Make fundamental interests of the broad masses of the people as the basis of social construction. Take achieving and maintaining the fundamental interests well as the departure point of the party and country. Promote people's livelihood construction and social construction. The purpose of this kind of social construction is to enable everyone has access to education, old-cage care, medical treatment and housing. Promote the construction of harmonious society in China. So adhere to the people-oriented concept of social construction is actually to strive to meet people's growing material and cultural needs, lay the historical position of Chinese people and focus on solving people's most important livelihood issues on the basis of developing productivity.

Adjusting from the perspective of benign optimization of social construction and management. Combine with the collective strength of the three departments, be scrupulous in separating public from private interests, make use of national power, shopping rights and social organization power to work together for socialist society management. Confirm the public power of the country comes from the power of people. Coordinate and adjust the relationship between the three departments. Establish a diversified, coordinated up and down power operating mechanism. From the perspective of benign optimization on social construction and building three structures to emphasize the strength of public participation and the function of non-rule. According to the function generated from social organization to explain its complement to government and market failure. Achieve the coordinated development of man and society. When protecting the free development of individual rights, do not ignore the re-shape of new type social governance ecology. Make social organizations and institutions as units to promote the ecological transformation of social governance and build a fast track for the three departments in government market and social organizations under the clear leadership of our party.

Adjusting on the functionality of social construction and management. For the adjustment on the functionality of social construction and management, it should be based on the science, education and other social undertakings which were self-established and joined by grass-roots, classifying managed non - profit public welfare social groups to coordinate and adjust the functionality of social organization and local government in social construction and management aspects. Establish and improve the relevant legal system of grassroots social organizations. Take coordinating the internal relations of people and meeting the various material and cultural life needs of urban and rural residents as the original intention. Strengthen necessary support force and formulate preferential policies to reverse the traditional social governance and construction function. In our country, benign functionality of social construction and management is based on goodwill and trust. Therefore, the party's governance should be a collection of formal rules and institutions. All governance principles and practices should be lawful. The top-down ruling power or pluralistic functionality should be transformed with concrete benign social construction and management collaborative needs. 


\section{Conclusion}

Good governance is an ideal governance state of benign society construction and management in the field of sociology of our country. It encourages the active participation of people and social organizations, constantly innovates and progresses in the concept of social governance. In the era of constantly updating and progressing social management concept, innovating and developing management pattern, the update of China's social management and construction concept should be based on a more comprehensive and coordinated view. From the perspective of national long-term stability, sustainable development, make achieving great rejuvenation of the nation as an important system guarantee. From the perspective of sociology, roundly and steadily understand the innovation mechanism of social management. Explore and think about public services is the right behavior of current social construction and management.

\section{Acknowledgements}

College issue: YJ1701, A Brief Discussion on How to Carry on Community Policing Work Effectively from the Strength Perspective Point of View

\section{References}

[1] L.P. Liu: Study on the Problems and Countermeasures of the Graduate Students' Employment in Sociology, (Dongbei University of Finance and Economics, China, 2016)

[2] J.M. Hu: Study on the Transformation of New Rural Governance from the Perspective of Fiscal Sociology, (Treasury Department of finance and science, China, 2014)

[3] M. Yang: Journal of Huazhong Normal University (Humanities and Social Sciences), (2014), No.5, p.14-22.

[4] Z.Q. Ding: Research on the Construction of Ideological and Political Education Carrier in Colleges and Universities from the Perspective of Sociology, (Jiangxi Agricultural University, China, 2012)

[5] H.S. Zheng, X. Tong: Social scientist, (2012), No.1, p.3-6.

[6] W. Yue: Leadership Digest, (2011), No.20, p.6-20.

[7] H.S. Zheng: Sociological Studies, (2011), No.4, p.12-21+242.

[8] S.Q. Shen: Liaoyuan daily, (2011), No.3.

[9] X.X. Bao: Theory Reference, (2011), No.3, p.48-50.

[10] X.X. Bao: Gansu Social Sciences, Information on 10.15891/j.cnki.cn62-1093/c.2010.05.046

[11] H.S. Zheng: Journal of renmin university of China, (2006), No.2, p.1-10.

[12] Y.R. Zhu: Study on the Sustainable Development of Urban Community Culture, ( Fujian Normal University, China, 2002) 